\title{
Percepção da internação em hospital psiquiátrico por pacientes com diagnóstico de esquizofrenia
}

Perception of psychiatric hospitalization by patients diagnosed with schizophrenia

Andrea Ruzzi Pereira*

Gabrielly Joazeiro**

\begin{abstract}
Resumo
O hospital psiquiátrico, apesar de não ser mais o centro da atenção em saúde mental, ainda é um recurso bastante utilizado nos casos de transtornos mentais mais graves, como a esquizofrenia. Com isso, esse trabalho objetivou conhecer a percepção dos próprios pacientes com esquizofrenia sobre a internação integral em uma dessas instituições. Trata-se de estudo exploratório descritivo, de abordagem qualitativa, cujos dados foram coletados em um hospital psiquiátrico por meio de entrevista semiestruturada. Participaram desta pesquisa oito pessoas com idade entre 24 e 52 anos, alguns com outros diagnósticos associados ao da esquizofrenia, sendo que todos já haviam sido internados anteriormente. Conclui-se que, enquanto uma porta de entrada nos momentos de crise psicótica, o hospital psiquiátrico tende a ser percebido pelos sujeitos entrevistados como um local para restabelecimento da saúde e um meio de acesso a alimentação, aos medicamentos necessários e às atividades de higiene.
\end{abstract}

Palavras-chave: Esquizofrenia. Hospitalização. Saúde Mental.

\begin{abstract}
The psychiatric hospital although is no longer the center of mental health attention, even so is a commonly used resource in cases of serious illnesses such as schizophrenia. Thus, this study aims to understand the perception of the person with schizophrenia on the full admission in one of these institutions. It is a descriptive exploratory study, of qualitative approach, whose data were collected in a psychiatric hospital through a semi-structured interview. Eight people, between the ages of 24 and 52, were interviewed; some with other diagnostics related to schizophrenia and all of them had been previously hospitalized. The findings imply that the psychiatric hospital, a gateway to health assistance in a psychotic crisis, is perceived as a place to restore health and means to access food, necessary medicines and hygiene facilities.
\end{abstract}

Keywords: Schizophrenia. Hospitalization. Mental Health.

DOI: $10.15343 / 0104-7809.20153904476483$

* Universidade Federal do Triângulo Mineiro - Uberaba - MG, Brasil. E-mail: nepsmad@gmail.com

** Universidade Federal do Triângulo Mineiro - Uberaba - MG, Brasil. E-mail: gabrielly_joazeiro@hotmail.com

Os autores declaram não haver conflitos de interesse. 


\section{INTRODUÇÃO}

Ao longo dos anos a humanidade tem enfrentado dificuldades em lidar com a diferença, o que pode ser observado no tratamento da loucura, que por vezes foi fundado na intolerância à conduta das pessoas com transtornos mentais, aprisionando-as em manicômios e hospitais psiquiátricos e afastando-as como forma de proteger a sociedade daquele que é considerado "diferente"

O hospital psiquiátrico pode ser caracterizado como uma instituição total, na medida em que é um local onde residem semelhantes que foram separados da sociedade mais ampla por determinado período de tempo, levando uma vida fechada e formalmente administrada. É também considerado um local de cuidado de pessoas que são consideradas incapazes de cuidar de si mesmas e que podem oferecer ameaças à sociedade, embora de maneira não intencional ${ }^{2}$.

Atualmente, a assistência oferecida em saúde mental é decorrente de muitas transformações sociais e políticas, que resultaram na desinstitucionalização dos doentes mentais. No cenário nacional, os hospitais psiquiátricos, que antes eram considerados os principais equipamentos de assistência à saúde e à pessoa em sofrimento mental, têm deixado de ser o centro da atenção para essas pessoas, dando espaço a uma nova rede de serviços extra hospitalares. Porém, mesmo com essa nova proposta de serviços substitutivos, esse equipamento ainda é um recurso bastante utilizado nos casos de doenças mais graves, em que há o transtorno mental associado a condições de risco ao doente e/ou a outras pessoas e, também, após terem sido esgotados os recursos extra hospitalares para atender a pessoa em crise $^{3}$.

No Brasil, utilizam-se as propostas da Reforma Psiquiátrica como diretrizes para saúde mental, buscando a diminuição do número de hospitais psiquiátricos e o aumento dos Centros de Atenção Psicossociais (CAPS) para atender pessoas com transtornos mentais. O Ministério da Saúde considera os CAPS como serviços substitutivos ao hospital psiquiátrico, que devem promover a desinstitucionalização da doença e do doente mental ${ }^{4}$.

A Reforma Psiquiátrica preconiza o tratamento extra hospitalar, comunitário e com base territorial. No início deste século, a Reforma foi questionada por ter fortes contornos de movimento político, não priorizando os aspectos técnicos da assistência ao doente mental, observando-se uma diminuição do número de leitos em hospitais psiquiátricos mais lenta do que o previsto por ela. Dessa forma, vários hospitais psiquiátricos continuavam (e continuam) mantendo em funcionamento seus leitos e sendo a porta de entrada principalmente de pessoas em processo de crise psicótica ${ }^{5}$.

Dentre os transtornos mentais, a esquizofrenia tem sido considerada um problema de saúde pública atual e tem exigido um investimento significativo por parte do sistema de saúde, causando sofrimento tanto para o doente quanto para o seu familiar ${ }^{6}$. É um dos transtornos psiquiátricos considerados graves e complexos. Por ser de caráter crônico, pode trazer perdas afetivas, sociais, relacionadas ao trabalho, e também gerar prejuízo e carga emocional e social ao familiar?.

A esquizofrenia é caracterizada por "distorções do pensamento e da percepção, inadequação e embotamento afetivo, ausência de prejuízo no sensório e na capacidade intelectual" $(p, 448)$. Esse transtorno atinge cerca de $1 \%$ da população mundial e seus sintomas podem ser divididos em positivos (alucinação, delírios e distúrbios do pensamento) e negativos (embotamento afetivo, anedonia, falta de motivação, entre outros) ${ }^{8}$.

Diante do encontrado na literatura, este trabalho propõe compreender o significado de estar institucionalizado em um hospital psiquiátrico para o próprio doente mental, visto que é em função deste que devem ocorrer mudanças no modo da assistência psiquiátrica. Com base nesses aspectos, esse estudo teve como objetivo conhecer a percepção da pessoa com esquizofrenia sobre a internação integral em um hospital psiquiátrico. 


\section{METODOLOGIA}

Esta pesquisa caracteriza-se como um estudo exploratório descritivo, de abordagem qualitativa, na qual se buscou descrever a situação do contexto em que foi feita a investigação ${ }^{9}$.

A pesquisa foi realizada em uma instituição de internação integral para o tratamento de pessoas em sofrimento mental, localizada em uma cidade do Triângulo Mineiro.

Os sujeitos foram definidos pelo critério de amostragem não probabilística de casos típicos, submetida à disposição de participação por parte das pessoas internadas no período da coleta de dados ${ }^{10}$, caracterizando-se por um grupo de oito. O conjunto das falas revelou semelhança.

Para realizarmos o convite de participação aos sujeitos, foi utilizada uma folha-controle da instituição, que continha dados referentes aos pacientes, tais como nome, médico responsável, data de internação e código da Classificação Internacional das Doenças (CID). Por meio desta folha, foi possível identificar todos os pacientes que tinham o diagnóstico de Esquizofrenia e que respondiam aos critérios de inclusão para a pesquisa. A inclusão dos participantes também considerou a seleção da assistente social da instituição, que nos deu acesso apenas aos casos considerados por ela com condições cognitivas para responder a entrevista.

Foram considerados critérios de inclusão para este estudo (a) ter diagnóstico de Esquizofrenia, fornecido pelo médico do serviço; (b) ter idade de 18 anos ou mais; e (c) concordar em participar da pesquisa, por meio da assinatura do Termo de Consentimento Livro e Esclarecido (TCLE). Os critérios de exclusão para a pesquisa foram (a) não responder aos critérios estabelecidos para inclusão na pesquisa; e (b) demonstrar não ter condições cognitivas de responder ao estudo.

Foi realizada uma entrevista piloto no mês de março e a coleta de dados ocorreu em maio de 2013, por meio de entrevista semiestruturada com questões fechadas e abertas, possibilitando que o indivíduo entrevistado pudesse discutir sobre o tema em questão sem se prender a pergunta formulada ${ }^{11}$.
No roteiro de entrevista elaborado pelas pesquisadoras, tinham questões relacionadas ao número de internações pelas quais o sujeito já havia passado, ao processo dessa internação, a percepção sobre a internação no hospital psiquiátrico e sobre o que o indivíduo conhece sobre tratamento extra hospitalar (CAPS).

Para a realização da análise de dados, as entrevistas foram submetidas à adaptação da análise de conteúdo temático-categorial para pesquisas qualitativas. As entrevistas foram gravadas e transcritas. Em seguida, os conteúdos foram decompostos para serem analisados em partes e distribuídos em categorias. Além disso, foi feita uma descrição do resultado da categorização, inferências e interpretação dos resultados obtidos com auxílio da fundamentação teórica adotada ${ }^{11}$.

A análise dos dados revelou quatro categorias: percepção sobre o adoecer; percepção sobre o momento da internação; percepção sobre o hospital psiquiátrico e percepção sobre o Centro de Atenção Psicossocial.

O desenvolvimento deste estudo seguiu todas as normas éticas norteadoras dos trabalhos que envolvem seres humanos, sendo aprovado pelo Comitê de Ética em Pesquisa da Universidade Federal do Triângulo Mineiro - UFTM, sob o parecer número 2338/2011.

\section{RESULTADOS}

No período da coleta de dados haviam 33 pessoas internadas, com diagnóstico de esquizofrenia. No entanto, apenas oito respondiam aos critérios de inclusão dessa pesquisa; destes, todos concordaram em participar. Os nomes dos sujeitos foram alterados para preservação da identidade.

Os sujeitos tinham idade entre 24 e 52 anos, três eram do sexo feminino e cinco do masculino. Nenhum deles estava internado pela primeira vez, e alguns possuíam outros diagnósticos associados ao de esquizofrenia, conforme apresenta a tabela 1 .

A partir da leitura exaustiva das falas dos sujeitos, pôde-se agrupá-las em quatro categorias: 
Tabela 1. Caracterização dos participantes. Uberaba - MG, 2013

\begin{tabular}{|c|c|c|c|c|}
\hline Sujeito & Idade & Sexo & Diagnóstico & $\begin{array}{l}\text { Número de } \\
\text { Internações }\end{array}$ \\
\hline Tereza & 52 anos & Feminino & $\begin{array}{l}\text { F20.0 } \\
\text { Esquizofrenia Paranoide }\end{array}$ & 22 internações \\
\hline Franco & 37 anos & Masculino & $\begin{array}{l}\text { F20.3 } \\
\text { Esquizofrenia Indiferenciada }\end{array}$ & 13 internações \\
\hline Pedro & 26 anos & Masculino & $\begin{array}{l}\text { F20.0 } \\
\text { Esquizofrenia Paranoide }\end{array}$ & 16 internações \\
\hline Nise & 42 anos & Feminino & $\begin{array}{l}\text { F20.3 + F19.2 } \\
\text { Esquizofrenia Indiferenciada + Transtornos mentais } \\
\text { e comportamentais devidos ao uso de múltiplas } \\
\text { drogas e ao uso de outras substâncias psicoativas. }\end{array}$ & 31 internações \\
\hline João & 47 anos & Masculino & $\begin{array}{l}\text { F20.3 + G40 } \\
\text { Esquizofrenia Indiferenciada + Epilepsia }\end{array}$ & 9 internações \\
\hline Cerqueira & 51 anos & Masculino & $\begin{array}{l}\text { F20.3 + F10.2 } \\
\text { Esquizofrenia Indiferenciada + Transtornos mentais } \\
\text { e comportamentais devidos ao uso de álcool. }\end{array}$ & 21 internações \\
\hline Isabel & 24 anos & Feminino & $\begin{array}{l}\text { F20.0 } \\
\text { Esquizofrenia Paranóide }\end{array}$ & 9 internações \\
\hline Clemente & 25 anos & Masculino & $\begin{array}{l}\text { F20.3 } \\
\text { Esquizofrenia Indiferenciada }\end{array}$ & 9 internações \\
\hline
\end{tabular}

\section{I - Percepções sobre o adoecer: a concepção} dos sujeitos sobre o processo de adoecimento perpassa pelo medo, angústia e insegurança, muitas vezes pela falta de compreensão de que as visões (alucinações), os delírios, a insônia e a necessidade de se isolar fazem parte do processo de adoecimento. Além disso, a tristeza e o choro frequente também foram relatados pelos sujeitos como percepção de que não estavam bem.

O conteúdo das falas revelou, também, que no início da doença os sujeitos não percebiam o que estava acontecendo; amigos ou familiares notaram a mudança e estimularam a procura pelo serviço de saúde.

Minhas colegas que perceberam que eu estava triste e me trouxeram pra cá porque viram que eu não estava bem (Tereza).

Eu chorava muito (Nise).

Eu sentia assim um pesadelo muito forte, meu olho ficou escuro, ficou preto. Sentia medo, pesadelo (Franco).

Começou com sete anos de idade quando eu comecei a dar crise. Ficava vendo pessoa entre a porta tentando por a língua (João).
Ah vontade de morrer, não gostava da família, ficava isolada sem fazer nada (Isabel).

II - Percepções sobre a internação atual: pelas falas dos sujeitos, observou-se que a maioria pediu pela internação, devido ao sofrimento que estavam sentindo, embora Tereza, Franco e Clemente, tenham sido levados por outra pessoa para serem internados.

Tereza, João, Cerqueira e Clemente não conseguiram expressar sua percepção quanto ao momento em que foram internados; já os outros revelaram terem sentido medo por pensarem que não iam sair mais do hospital, revolta pelo autoritarismo de alguns profissionais, saudade dos familiares e a necessidade de acolhimento. A internação atual foi vista também como uma opção para sobrevivência, visto que alguns sujeitos estavam passando fome e procuraram o hospital psiquiátrico por saberem que seria oferecida alimentação. Além disso, a escolha pela internação foi descrita como uma forma de distanciamento de alguns vícios e como um meio de conter situações de agressividade. 
Sentia o corpo ruim e também a necessidade de alguém para me acalmar (Isabel).

Medo. Achava que eu ia morar aqui, achava que eu não ia sair daqui nunca mais. Sentia muito medo (Franco).

Eu senti saudade da minha família (Nise).

É, porque tem comida aqui sabe, tem comida, tem café, tem comida cinco vezes por dia alguns pacientes têm que a tomar a medicação,
Eu tava querendo vim pra cá desde o dia que eu saí daqui. Ficava uma tomação de pinga lá fora, cigarro... (Cerqueira).

\section{III - Percepções sobre o hospital psiquiátri-} co: as percepções variam entre as necessidades reais que os indivíduos têm na vida às emoções subjetivas acerca do hospital. Assim, o hospital psiquiátrico pôde ser visto de forma positiva por oferecer alimentação nos horários certos e medicação adequada, além de pessoas sensíveis que proporcionam acolhimento e uma boa conversa; como também foi considerado um local de opressão, referindo-se aos momentos em que mesmo que manifestem não querer.

[No hospital tem] covardia de um lado e ajuda do outro. Covardia porque na hora do remédio tem uns que não quer tomar, eles enforcam, abre a boca e soca o dedo pra dentro da garganta, a pessoa toma o remédio, muitas vezes toma a força, dá injeção. Ajuda porque tem comida, tem conversa, algumas pessoas tem coração, algumas pessoas tem sentimento, chora sabe? (Pedro). Eu gosto daqui. Ah não, não tenho nada a reclamar. Você tem o pão, tem remédio, tem comida, café, roupa lavada, banho, dorme cedo, tudo, tudo na hora certa (Pedro).

A internação também é considerada necessária para remissão de sintomas e melhoria da saúde; e o hospital psiquiátrico também é visto como um lugar que proporciona cuidado, mas às vezes, considerado como um ambiente ruim por gerar medo.

Preciso, preciso porque eu fico pensando coisas ruim (Nise).

Eles tratam eu bem, não bate na gente, nos pacientes. Aqui é bom que melhora a saúde da pessoa, melhora né?... Ambiente ruim né (João).

Muito bom, melhor que essas outras clínicas particular, todas. Nota 10 pro sanatório, 10 mesmo. Penso que todo mundo faz bem pelo jeito de ser, só pelo jeito de ser. Eles me tratam bem demais (Cerqueira).

Eu acho ruim, me dá um corpo ruim, uma moleza, fraqueza totalmente, desequilíbrio (Isabel).

O sanatório até tem coisa boa, mas só que é ruim ficar aqui né. Eu fico pensando que os outros vai matar eu (Clemente).

IV - Percepção sobre os serviços substitutivos: todos os participantes da pesquisa já haviam ouvido falar sobre o CAPS. No entanto, nem todos haviam feito uso desse dispositivo. Dos que já realizaram acompanhamento no CAPS, alguns relataram ter gostado muito do serviço oferecido, demonstrando, inclusive, interesse em retornar ao tratamento após a internação. Em contrapartida, o descaso com o tratamento oferecido também pôde ser percebido, tendo sido relatado o descarte da medicação fornecida. Foi relatada ainda a dificuldade de convivência com outros usuários do CAPS, o que conduz a não adesão aos tratamentos oferecidos nesse dispositivo.

Já. Adorei (Nise).

Ouvi falar só que eu não conheço não (João). Todo dia vou lá tomar café e comer pãozinho (Clemente).

Eu já fiz tratamento no Maria Boneca. Foi bom lá eu gostei de lá. Você podia arrumar pra mim lá, tem jeito de você arruma pra mim não? (Franco).

Já, já fiz já. Tomava oito injeção lá e três saco de remédio eles me dava. Eu jogava tudo fora, falava: o que eu vou fazer com isso, com essa porcaria aqui? Era CAPS D, psicoantissocial porque eu sempre fui antissocial com todo mundo (Pedro).

\section{DISCUSSÃO}

A percepção da doença mental é subjetiva, mas este estudo pode discutir as observações de cada um dos entrevistados, o que permite 
verificar que eles percebem a doença mental como uma realidade composta de sofrimento e dificuldade, tais como tristeza e angústia. Também atribuem à doença sintomas como agitação, delírios, alucinação, entre outros. Além disso, os entrevistados relataram o isolamento, que pode ser compreendido tanto como um sintoma da doença como algo relacionado ao autoestigma ${ }^{12}$.

Na ocorrência de episódio psicótico, o sujeito se distancia do mundo real em decorrência de mudanças no pensamento, conduta e percepção. Esses sintomas trazem bastante sofrimento, desespero, nervosismo e atrapalham o cotidiano dos indivíduos com sintomas psicóticos, além de causar estranhamento à sociedade, fazendo com que a pessoa com doença mental se isole do convívio social para não demonstrar o sofrimento que enfrenta ${ }^{12}$.

O sofrimento gerado pelos sintomas da esquizofrenia fez com que alguns sujeitos optassem pela internação psiquiátrica, procurando amenizar ou cessar tal sofrimento. Outros, encontraram na internação atual um meio de sobrevivência e uma forma de se distanciarem de alguns vícios e de conter a agressividade. Nesse sentido, outro estudo ${ }^{1}$ realizado com pessoas com transtornos mentais após terem alta da internação psiquiátrica traz resultados que se assemelham aos encontrados na presente pesquisa, uma vez que os principais motivos que levaram à internação recente dos sujeitos entrevistados eram ideação suicida, sintomas psicóticos (delírio, alucinação, mania) e agressividade. Dentre esses motivos, apenas a ideação suicida não foi trazida na fala dos indivíduos entrevistados no presente estudo.

Uma característica comum às pessoas em sofrimento mental, diagnosticadas com esquizofrenia, são as frequentes reinternações psiquiátricas. Todos os sujeitos entrevistados já haviam sido internados por mais de uma vez. Sobre esse fato, pode-se ressaltar que apesar dos avanços nos serviços substitutivos, o doente mental ainda passa por um processo chamado porta giratória, caracterizado por sucessivas internações nos períodos de episódios agudos ${ }^{13}$.
Para muitos pacientes e familiares a internação é uma forma bem vista de tratamento. Demonstram ter dependência do hospital psiquiátrico em razão de um cotidiano programado, com horários rígidos para tomar medicamentos, alimentação e outras rotinas de cuidado ${ }^{4}$. Esta dependência a um cotidiano programado emergiu na fala de alguns sujeitos que relataram como um aspecto positivo do hospital psiquiátrico o cumprimento das atividades diárias em horários "certos".

A opção pela internação psiquiátrica também foi trazida na fala de alguns sujeitos como um meio de sobrevivência frente às dificuldades socioeconômicas. Outro estudo realizado com pacientes crônicos em processo de institucionalização observou uma proximidade com os resultados encontrados nessa pesquisa, visto que grande parte dos pacientes institucionalizados se encontravam no hospital psiquiátrico por questões sociais, familiares ou por falta de condições econômicas de sobrevivência extra hospitalares, fazendo com que o hospital seja entendido muitas vezes como um local de proteção $^{14}$.

Apesar de todos os participantes conhecerem o Centro de Atenção Psicossocial (CAPS), eles relataram dificuldade em se adaptarem e se vincularem de fato a esse dispositivo, não aderindo aos tratamentos oferecidos, o que pode ter facilitado as reinternações psiquiátricas. Considerando o recorrente processo de internações vivenciadas pelos indivíduos, é necessário ainda levar em consideração o tipo de tratamento ofertado nos CAPS, que pode não atender as expectativas e demandas individuais dessas pessoas, bem como a motivação do usuário de busca de tratamento extra hospitalar e o apoio familiar.

Os sujeitos provenientes de longas internações comumente encontram dificuldades de vinculação e adaptação ao CAPS, exigindo que a equipe desses serviços negocie com seus familiares, com os profissionais do hospital ao qual estão ligados, além de serem flexíveis no que diz respeito ao projeto terapêutico. Esses sujeitos trazem sequelas geradas pela 
institucionalização e necessitam de estratégias complexas de intervenção ${ }^{15}$.

Um trabalho realizado com pacientes que passaram pela internação e que atualmente se encontram em acompanhamento em um CAPS, indica que, após ingressarem em tratamento neste dispositivo, nenhum dos sujeitos foi internado novamente; isto indica que o cuidado proposto na instituição possibilitou mudanças. Além disso, evidenciou-se a diferença entre o modelo de tratamento asilar e o psicossocial, seja pelo maior contato com os profissionais ou pelo maior tempo na instituição, o que acarretou um relacionamento de confiança e outro modo de acolher as crises psicóticas ${ }^{16}$.

Desse modo, a efetivação das intenções e ações dos CAPS não se dá apenas pela mudança do tipo de serviço oferecido. Transformações profundas nas práticas em saúde mental exigem a concretização de uma rede de cuidados que compreenda o território, a integralidade e a participação popular ${ }^{17}$.

\section{CONCLUSÃO}

O hospital psiquiátrico ainda é uma porta de entrada para pessoas com diagnóstico de esquizofrenia nos momentos de crise psicótica. Após várias internações e considerando os prejuízos que a esquizofrenia traz, os sujeitos ainda se mostram dependentes deste equipamento. A instituição representa não só um local para o restabelecimento da saúde, mas um meio pelo qual podem ter acesso à alimentação, aos medicamentos necessários e às atividades de higiene. Além disso, apesar da maioria dos sujeitos conhecerem ou terem feito uso dos CAPS, isso não influenciou na efetiva redução de internações no hospital psiquiátrico.

Por meio deste estudo pode-se compreender melhor a percepção de pessoas diagnosticadas com esquizofrenia com relação à internação integral em hospital psiquiátrico. No entanto, este estudo se limita à percepção apenas de sujeitos com um determinado transtorno mental, não sendo possível inferir que as percepções aqui descritas são as mesmas ou semelhantes às de outras pessoas internadas em hospital psiquiátrico.

Por fim, ressalta-se a importância de estudos nessa área para que as percepções das pessoas com transtornos mentais possam ser levadas em consideração nos diversos locais em que este público está inserido e no planejamento das estratégias de atenção à pessoa em sofrimento mental e avaliação das políticas públicas que atendem às necessidades dessa população.

\section{REFERÊNCIAS}

1. Cardoso L, Galera SAF. Internação psiquiátrica e a manutenção do tratamento extra-hospitalar. Rev Esc Enferm USP. [Internet]. 2011 [citado 20 jul 2012]; 45(1):87-94. Disponível em http://www.scielo.br/pdf/reeusp/v45n1/12.pdf

2. Goffmam E. Manicômios, prisões e conventos. 8 ed. São Paulo: Perspectiva; 2008. As características das instituições totais; p. 13-23.

3. Cardoso L, Galera SAF. Quem são os egressos de internação psiquiátrica? Acta Paul Enferm. [Internet]. 2009 [citado 20 jul 2012]; 22(6):733-40. Disponível em: http://www.scielo.br/pdf/ape/v22n6/a02v22n6.pdf.

4. Salles MM, Barros S. Reinternação em hospital psiquiátrico: a compreensão do processo saúde/doença na vivência do cotidiano. Rev Esc Enferm USP. [Internet]. 2007 [citado 20 jul 2012]; 41(1):73-81. Disponível em: http://www.scielo.br/ pdf/reeusp/v41n1/v41n1a09.pdf

5. Scherer ZAP, Scherer EA. O doente mental crônico internado: uma revisão da literatura. Rev Latinoam Enferm. [Internet]. 2001 [citado 14 ago 2012]; 9(4):56-61. Disponível em: http://www.scielo.br/pdf/rlae/v9n4/11484.pdf

6. Zanetti ACG, Galera SAF. O impacto da esquizofrenia para a família. Rev gaúch enferm. [Internet]. 2007 [citado 14 ago 2012]; 28(3):385-392. Disponível em: http://seer.ufrgs.br/index.php/RevistaGauchadeEnfermagem/article/view/4689/2596 7. Santana AFFA, Chianca TCM, Cardoso CS. Qualidade de vida de pacientes com esquizofrenia internados em hospital de custódia. J bras psiquiatr. [Internet]. 2009 [citado 14 ago 2012]; 58(3):187-194. Disponível em: http://www.scielo.br/ pdf/jbpsiq/v58n3/08.pdf

8. Costa JAS, Andrade KVF. Perfil dos usuários incluídos no protocolo de esquizofrenia em um programa de medicamentos do componente especializado da assistência farmacêutica. Rev baiana saúde pública. [Internet]. 2011 [citado 20 set 2012 ]; 35(2):446-456. Disponível em: http://inseer.ibict.br/rbsp/index.php/rbsp/article/viewFile/317/pdf_126

9. Gil AC. Como elaborar projetos de pesquisa. 5 ed. São Paulo: Atlas; 2010. 
10. Sampieri RH, Collado CF, Lucio PB. Metodologia de pesquisa. 3 ed. São Paulo: McGraw-Hill; 2006.

11. Minayo MCS. O desafio do conhecimento: pesquisa qualitativa em saúde. 11 ed. São Paulo: HUCITEC; 2008.

12. Gasparini D, Costa HM, Hildebrandt LM, Van Der Sand ICP, Piosevan SMS, Leite MT. A doença mental na voz de indivíduos psicóticos. Rev Contexto \& Saúde [Internet]. 2011 [citado 10 abr 2013]; 10(20):559-563. Disponível em: https:// www.revistas.unijui.edu.br/index.php/contextoesaude/article/view/1578/1333

13. Cardoso L, Galera SAF. O cuidado em saúde mental na atualidade. Rev Esc Enferm USP. [Internet]. 2011 [citado 18 maio 2013]; 45(3):687-691. Disponível em: http://www.scielo.br/pdf/reeusp/v45n3/v45n3a20.pdf.

14. Machado V, Manço ARX, Santos MA. A recusa à desospitalização psiquiátrica: um estudo qualitativo. Cad saúde pública. [Internet]. 2005 [citado 18 maio 2013]; 21(5):1472-1479. Disponível em: http://www.scielo.br/pdf/csp/v21n5/20.pdf 15. Pande MNR, Amarante PDC. Desafios para os Centros de Atenção Psicossocial como serviços substitutivos: a nova cronicidade em questão. Ciênc saúde coletiva. [Internet]. 2011 [citado 21 jul 2013]; 16(4):2067-2076. Disponível em: http://www.scielo.br/pdf/csc/v16n4/v16n4a06.pdf

16. Bichaff R. A percepção do usuário sobre o modelo assistencial. In: $3^{\text {a }}$ Conferência Nacional de Saúde Mental: cuidar sim, excluir não [Internet]; dez. 2001 [citado 21 jul 2013]. Brasília: Ministério da Saúde; 2002. p. 160-167 (Caderno Informativo; série D, n. 15). Disponível em: http://bvsms.saude.gov.br/bvs/publicacoes/3_conf_mental.pdf.

17. Leão A, Barros S. Território e serviço comunitário de saúde mental: as concepções presentes nos discursos dos atores do processo da reforma psiquiátrica brasileira. Saúde soc. [Internet]. 2012 [citado 21 jul 2013]; 21(3):572-586. Disponível em: http://www.revistas.usp.br/sausoc/article/view/48746/52820

Recebido em 14 de abril de 2014. Aprovado em 27 de setembro de 2015. 